\title{
A pregnant woman with primary hyperparathyroidism:
}

\section{a case report}

\author{
Goknur Yorulmaz', Nur Kebapci², Kevser Onbasi³, Belgin Efe'2, Aysen Akalin² \\ ${ }^{1}$ Department of Endocrinology and Metabolism, Eskisehir State Hospital, Eskisehir, Turkey \\ ${ }^{2}$ Department of Endocrinology and Metabolism, Osmangazi University Medical School, Eskisehir, Turkey \\ ${ }^{3}$ Department of Endocrinology and Metabolism, Dumlupinar University Medical School, Evliya Celebi Training and Research \\ Hospital, Kutahya, Turkey
}

\begin{abstract}
Primary hyperparathyroidism is diagnosed with an increase of calcium levels and a decrease in phosphorus levels. Primary hyperparathyroidism is a rare condition in pregnancy. Calcium levels tend to be low in pregnant women, and high levels of calcium can point a primary hyperparathyroidism. Here, we report an original case of a pregnant woman with primary hyperparathyroidism who was fully healed after the surgery. A 30-year-old pregnant women $\left(10^{\text {th }}\right.$ gestational week $)$, admitted to the endocrinology department for management of thyrotoxicosis, when high calcium levels $(11.8 \mathrm{mg} / \mathrm{dL})$ were found in the laboratory tests. The parathyroid hormone level was $135 \mathrm{pg} / \mathrm{ml}$. Ultrasound imaging revealed a parathyroid adenoma $(12 \times 7 \times 27 \mathrm{~mm})$. She had maintained high calcium levels despite the medical treatment, for this reason, she had surgery in the second trimester. Our case was diagnosed early due to early recognition of calcium elevation. The mother and the foetus had not any complication. Pregnant women tend to have low calcium levels hence if a hypercalcemia situation appears in pregnant women; primary hyperparathroidism has to be suspected.
\end{abstract}

Eur Res J 2016;2(1):77-79

Keywords: Pregnancy; hypercalcemia; hyperparathyroidism

\section{Introduction}

Parathyroid hormone (PTH) is a peptide hormone that regulates the calcium levels in blood and extracellular fluid in the human body. Primary hyperparathyroidism (PHP) is diagnosed with the increase of the calcium levels and the decrease of the phosphorus levels. The PTH measurement shows high levels in this situation. Urinary calcium excretion is also increased. Adenoma is detected in $85 \%$ of cases $[1,2]$. Calcium levels are detected low in pregnant women due to hypoalbuminemia, passage of the calcium to the placenta and increased glomerular filtration rate [3]. High levels of calcium can point a PHP in pregnant women. PHP is a rare condition in pregnancy but causes complications for the mother and the foetus. Maternal complications include hyperemesis, muscle weakness, mental status changes, hypercalcemic crisis, bone disease, nephrolithiasis, and pancreatitis. Reported foetal complications 
include intrauterine growth retardation, low birth weight, preterm delivery, intrauterine foetal demise, neonatal postpartum tetany, and permanent hypoparathyroidism [4]. Fortunately, prompt diagnosis and effective management can improve outcomes for both. Here, we report an original case of pregnancy with primary hyperparathyroidism that was diagnosed in the course of routine laboratory examination and healed completely after the surgery.

\section{Case Presentation}

A 30 -year-old pregnant women $\left(10^{\text {th }}\right.$ gestational week) admitted to the endocrinology department for management the thyrotoxicosis that was determined during the routine laboratory tests that were performed by her gynaecologist. She had been diagnosed with hyperemesis gravidarum and was considered to have gestational thyrotoxicosis in the first step of the medical procedure, but high calcium levels (11.8 $\mathrm{mg} / \mathrm{dL}$ ) were noticed in the laboratory tests. There was no history of hypercalcemia and her family history also did not reveal any case of hypercalcemia or any endocrine tumours. The PTH and the calcium levels were tested again, but the results were high as same as the first test results. The results were $135 \mathrm{pg} / \mathrm{ml}$ and $11.6 \mathrm{mg} / \mathrm{dl}$ respectively. Urinary calcium excretion rate was $456 \mathrm{mg} / \mathrm{per}$ day. Tubular phosphorus reabsorption rate was $91 \%$, and the chlor-phosphorus ratio was 41.3. In the light of all these data, primary hyperparathyroidism was diagnosed.

Ultrasound imaging revealed a parathyroid adenoma $(12 \times 7 \times 27 \mathrm{~mm})$ at the inferior of the right thyroid lobe (Figure 1).

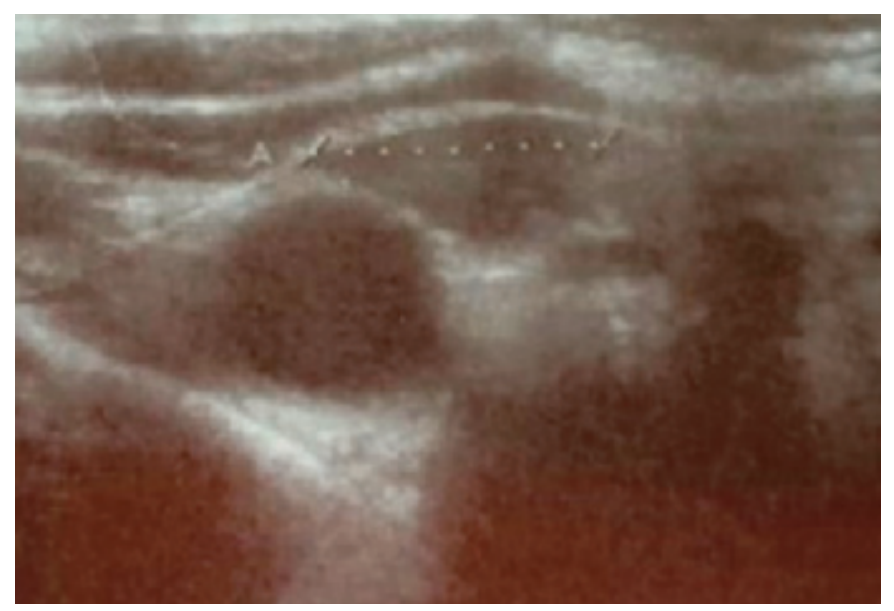

Figure 1. Ultrasound imaging revealed a parathyroid adenoma $(12 \times 7 \times 27 \mathrm{~mm})$ at the inferior of the right thyroid lobe
The patient was treated with calsitonin and hydration during the first trimester. She had maintained high calcium levels despite the medical treatment, and underwent surgery for the parathyroid adenoma in the second trimester. Histopathological examination confirmed the diagnosis of a parathyroid adenoma (Figure 2-3).

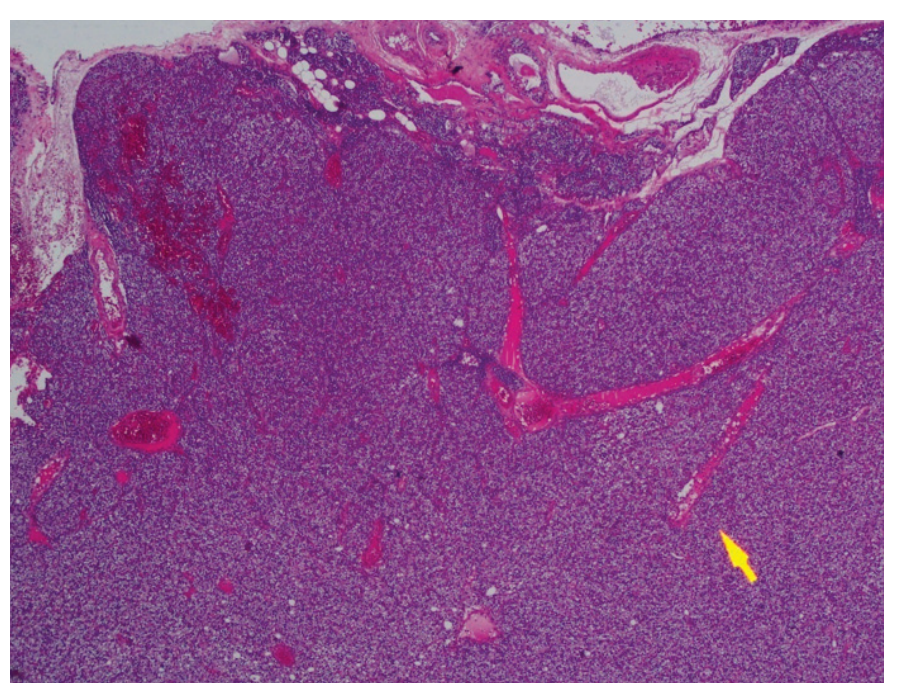

Figure 2. This parathyroid adenoma shows a rim of atrophic parenchyma at he periphery with only an attenuated capsule noted (H\&E, x40)

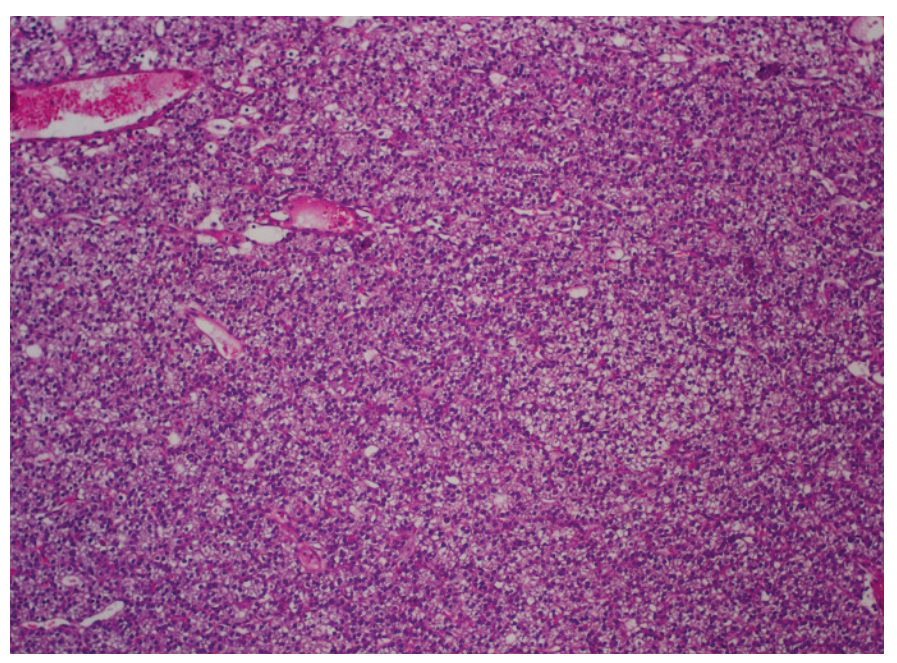

Figure 3. Chief cells compose this adenoma without any fat cells present. (H\&E, x100)

The calcium levels turned to normal after the surgery, and the results were normal during the pregnancy. Similarly, the mother and the new-born did not have any complication associated with hypercalcemia after the birth. 


\section{Discussion}

Primary hyperparathyroidism may cause complications for the mother and the foetus, because of this early intervention is vital during the pregnancy. The miscarriage rate is increased by 3.5 -fold associated with this disease [5]. The abortions generally occur in the $2^{\text {nd }}$ trimester. Surgical intervention is recommended in the $2^{\text {nd }}$ trimester for patients whose calcium levels more than $11.4 \mathrm{mg} / \mathrm{dL}$ $[5,6]$. If the patient approaches the $3^{\text {rd }}$ trimester and has mild hypercalcemia, medical treatment is recommendable [7]. If severe hypercalcemia exists, diuretic therapy can be used [8]. Magnesium sulphate was reported to be effective in pregnant women with acute pancreatitis [9]. Phosphate was used to treat hypercalcemia in the past, but it is not suggested anymore $[4,10,11]$. Currently, there are case studies showing benefit from the calcitonin and cinacalcet. Both drugs are group $\mathrm{C}$ for pregnancy. Calcitonin therapy has limited efficacy and has a risk of tachyphylaxis [11-14]. Medical treatment that can be given to patients limited and we do not know all the adverse events. Therefore, early detection and surgical removal of adenoma in the second trimester is critical if it is necessary.

Calcium levels tend to be low during pregnancy. Unusually high levels of calcium can become an alert symptom in a pregnant patient. Thus, there will be a chance to prevent the development of complications for the mother and the foetus. Ultrasonography is a valuable imaging modality for detecting the parathyroid lesions when primary hyperparathyroidism is diagnosed. Our patient had her diagnose at early stages before the complications. She had no benefit from hydration and calcitonin. Surgery was performed in the second trimester. The abnormalities of calcium were not detected after the surgery during pregnancy and after the birth.

\section{Conclusion}

Our case is a patient who was diagnosed in time thanks to early recognition elevated calcium levels. The mother and the foetus had not any complication. Pregnant women tend to have low calcium levels hence if a hypercalcemia situation appears in pregnant women, primary hyperparathyroidism has to be suspected.

\section{Informed Consent}

Written informed consent was obtained from the patient for the publication of this case report.

\section{Conflict of interest}

The authors declared that there are no potential conflicts of interest with respect to the research, authorship, and/or publication of this article.

\section{References}

[1] Bringhurst FR, Demay MB, Kronenberg HM.Hormones and disorders of mineral metabolism. In:Williams Textbook Of Endocrinology tenth edition. Philadelphia: Saunders, 2003:1303-73.

[2] Wysolmersky J.J, Insogna KL. The parathyroid glands, hypercalcemia and hypocalcemia. In: Goldman L, Ausiello D. Cecil textbook of medicine 23rd edition. Philadelphia: Saunders, 2008:1897906.

[3] Breslau NA, Zerwekh JE. Relationship of estrogen and pregnancy to calcium homeostasis in pseudohypoparathyroidism. J Clin Endocrinol Metab. 1986 Jan;62(1):45-51.

[4] Schnatz PF, Curry SL. Primary hyperparathyroidism in pregnancy: evidence-based management. Obstet Gynecol Surv. 2002 Jun;57(6):36576.

[5] Norman J, Politz D, Politz L. Hyperparathyroidism during pregnancy and the effect of rising calcium on pregnancy loss: a call for earlier intervention. Clin Endocrinol (Oxf). 2009 Jul;71(1):104-9.

[6] Carella MJ, Gossain VV. Hyperparathyroidism and pregnancy: case report and review. J Gen Intern Med. 1992 Jul-Aug;7(4):448-53.

[7] Kelly TR. Primary hyperparathyroidism during pregnancy. Surgery. 1991 Dec;110(6):1028-33.

[8] Croom RD 3rd, Thomas CG Jr. Primary hyperparathyroidism during pregnancy. Surgery. 1984 Dec;96(6):1109-18.

[9] Rajala B, Abbasi RA, Hutchinson HT, Taylor T. Acute pancreatitis and primary hyperparathyroidism in pregnancy: treatment of hypercalcemia with magnesium sulfate. Obstet Gynecol. 1987 Sep;70(3 Pt 2):460-2.

[10] Montoro MN, Collea JV, Mestman JH. Management of hyperparathyroidism in pregnancy with oral phosphate therapy. Obstet Gynecol. 1980 Apr;55(4):431-4.

[11] Herrera-Martínez AD, Bahamondes-Opazo R, Palomares-Ortega R, Muñoz-Jiménez C, Gálvez-Moreno MA, Quesada Gómez JM. Primary hyperparathyroidism in pregnancy: a two-case report and literature review. Case Rep Obstet Gynecol. 2015;2015:171828.

[12] Horjus C, Groot I, Telting D, van Setten P, van Sorge A, Kovacs $\mathrm{CS}$, et al. Cinacalcet for hyperparathyroidism in pregnancy and puerperium. J Pediatr Endocrinol Metab. 2009 Aug;22(8):741-9.

[13] Som M, Stroup JS. Primary hyperparathyroidism and pregnancy. Proc (Bayl Univ Med Cent). 2011 Jul;24(3):220-3.

[14] Dochez V, Ducarme G. Primary hyperparathyroidism during pregnancy. Arch Gynecol Obstet. 2015 Feb;291(2):259-63. 